\title{
Climate change and sea level rise impacts at ports and a consistent methodology to evaluate vulnerability and risk
}

\author{
S. Messner, L. Moran, G. Reub \& J. Campbell \\ ENVIRON International Corp, USA
}

\begin{abstract}
A growing number of public and private entities, including port authorities, are evaluating potential impacts from climate change and are developing procedures to incorporate the financial and other risks into their investment decision making processes. This paper explores an evaluation framework for climate change adaptation with a case study at one port that incorporates information from historical tide measurements and storm events, sea level rise projections, digital elevation surveys of nearshore areas, and localized protection/armouring not reflected in elevation surveys to develop more detailed and accurate projections of sea level rise on port facilities and areas adjacent to Ports. After inclusion of key infrastructure, ecological, and land use information into a GIS model of the area, the projections can then be used to more accurately assess vulnerabilities and risks from sea level rise, storms, and floods in port areas. Ports are a critical intersection point of global commerce and are highly vulnerable to future increases in sea level rise and storminess. Much is potentially at stake approximately $75 \%$ of all global trade by weight occurs by maritime transport and $59 \%$ by value. The paper also explores a methodology to evaluate risks in a common financial format as part of a Net Ecosystem Services Analysis (NESA). It considers the unified NESA valuation as a powerful framework that can incorporate the full suite of issues (social, economic and environmental) for decision making when quantifying costs and benefits across a variety of land use types.
\end{abstract}

Keywords: Port of San Diego, sea level rise, NESA, climate change, climate action plan. 


\section{Introduction}

Climate change will directly affect public and private operations and transportation in coastal areas through physical changes such as sea level rise, flooding and increased storm events. Climate change will also affect a broad range of additional activities related to ports and the coastal environment including chemical changes (ocean acidification), biological changes (habitat and species distribution), and ultimately how humans use natural resources. This will have substantial financial and human use implications around ports including facilities expansion and maintenance, human health and safety, tourism and recreation (e.g. fishing, bird watching, site seeing etc.), and general ecosystem health that provide these services to humans.

A growing list of port operators, including US ports in San Diego and New York/New Jersey, are developing strategies to deal with the impacts of climate change. These ports have recognized the need for consistent methodologies to evaluate risk and the quantitative cost-benefit analyses that support risk determinations. The Port Authority of New York and New Jersey has developed strategies to deal with extreme weather and sea level rise and call for these strategies to be supported quantitatively to the extent possible (1). In the aftermath of Hurricane Sandy and its impacts on the Port, lessons learned by the Port and its tenants will be applied to previous planning work (2).

Similarly, The Port of San Diego is a trustee of the tidelands and submerged lands of San Diego Bay and therefore has a responsibility to plan and prepare for the future use of these lands, including planning for and adapting to climate change. The impacts of climate change posing potential threats to the Port include repeated and/or long-term inundation of low lying areas due to sea level rise (SLR), drought, water shortage, storm intensification, flooding, and temperature increases. Based on the Port's location, operational activity, and on planning work conducted to date, SLR is the primary climate change impact which will affect the Port.

This paper explores an evaluation and decision making framework for climate change adaptation that first incorporates relevant historical information and climate projections into an evaluation framework for determination of physical vulnerabilities, and second incorporates financial risk information relevant to ports and maritime transport. The financial risk evaluation considers the implementation of a unified Net Ecosystem Services Analysis (NESA) valuation as a powerful framework that can incorporate the full suite of issues (social, economic and environmental) for decision making when quantifying costs and benefits across a variety of land use types.

\section{Climate change and challenges to port and the maritime industry}

Ports and the maritime transport industry have long been a critical link for commerce in the United States and the world. Approximately $75 \%$ of all global trade by weight occurs by maritime transport and $59 \%$ by value [2]. US exports 
through ports grew in value by $121 \%$ between 2003 and 2010 [3] to $\$ 455$ billion. US imports through ports grew by $61 \%$ in the same time period to $\$ 978$ billion. Port commerce accounts for 13.3 million jobs in the United States and each $\$ 1$ billion in new exports shipped though seaports accounts for 6,000 US jobs [4].

In addition to their vital role in global maritime commerce, port authorities are often responsible for adjacent or interrelated activities such as airports, bridges, tunnels, industrial parks, natural lands, public marinas, and public recreational facilities (beaches, parks). As stewards for many or all of these activities, port authorities will face challenging decisions on how to manage risks for these activities with future increases in sea level rise resulting from climate change. For example, decisions to protect existing maritime operations could have adverse effects on adjacent beaches and tourism income. Similarly, adjacent natural lands that support wildlife and beneficial ecosystem functions could become entirely inundated without a coordinated planning effort to manage coastal resiliency at a regional level.

\subsection{Decisions of the future: seawalls, elevation, relocation, habitat restoration?}

Projected ranges of sea level rise (SLR) over the next century vary from $0.75-$ 1.9 meters [5]. If sea levels rise nearly two meters by 2100 , many ports will face regular inundation during storm events. Recent work by Scripps [6] indicates that storm events faced by ports on the west coast on an annual basis could become weekly events. An east coast study from 2007 [7] discusses the possibility of significantly higher storm surges by 2100. This work now appears even more pertinent after the impacts of Hurricane Sandy. To develop better resiliency to inundation and flooding, ports appear to have some fundamental choices. The choices for port activities are to build coastal armouring such as seawalls and dikes, to elevate the entire port area, or to relocate to a nearby area with sufficient elevation to accommodate future commerce. More compact ports can focus on one of the options - for example the Port of Gulfport (Mississippi) as part of its redevelopment after Hurricane Katrina plans to elevate its operations by 4.5 meters to raise the port out of the future floodplain. These elevation plans have been downscaled from 7.5 meters as project planning has progressed. Larger ports may need to consider a combination of these strategies - e.g. some operations may be able to be raised or armoured at the current location and some may need relocation to higher ground.

Each of these options has cost/benefit trade-offs. Dikes and coastal armouring can cause environmental problems such as increased erosion along adjacent shorelines and related habitat degradation and may not address increased flooding risk from stormwater runoff. Elevating an entire port will require large volumes of fill and does not address the possible need to protect the infrastructure to link the port with the transportation network. Relocation of the port would be disruptive to local economies and could result in new and significant environmental impacts in the relocation areas. 


\subsection{Sea level rise uncertainties}

The range in SLR projections for the coming century adds to the planning challenges faced by ports and other coastal region decision makers. Although it is prudent to consider higher end projections to assess regional vulnerabilities to climate change - e.g. 1.5 meters of SLR plus 100 year storm surge was considered for the Sea Level Rise Adaptation Strategy for San Diego Bay [8] any resulting economic decisions will be skewed to a single high end scenario. To account for this, previous evaluation methods have considered a small number of scenarios of future sea level rise as well as potential increases in storminess which can then be used to help estimate vulnerability and risk. For example, [9] ranked the potential exposure of 136 port cities worldwide to climate impacts in the years 2005 and 2070 and developed scenarios that include variations in mean sea level, storminess (focusing on the 100 year event), patterns of urbanization and economic growth, and human-induced subsidence. Even in doing this, the scenarios include what were termed high-end estimates for each of these factors.

An approach for economic investment decisions that considers a fuller range of SLR scenarios, as well as potential changes in related climatic variables such as storminess, is presented in [10]. This study considered investment decisions at the Port of Los Angeles, and used Robust Decision Making (RDM) analysis to consider a fuller range of climatic variables to provide guidance for current and future investment decisions at the Port related to sea level rise. The case study discussed below considers two SLR scenarios in the analysis; however with sufficient budget a port or other coastal jurisdiction may choose to evaluate a fuller range of scenarios as is presented in the Port of Los Angeles study.

\section{Case study: Port of San Diego}

While nations and states develop programs to address climate change, many local jurisdictions are addressing climate change on a smaller scale by developing climate action plans (CAPs). In autumn 2010, the Port of San Diego began development of a Climate Mitigation and Adaptation Plan (called the Climate Plan) to identify, assess, and develop strategies to help reduce GHG emissions and address local vulnerabilities to climate change [13]. The Climate Plan is also planned to help streamline the evaluation of climate change issues required by the State of California's Environmental Quality Act (CEQA) for future planning.

There is currently no template for climate adaptation planning at a port. There are many aspects that are unique to ports compared to cities or counties. For example, the Port does not have authority over many of the sources that are responsible for its greenhouse gas (GHG) emissions in the same way that a city or county might have permitting or land use control over similar sources. For example, a city may be able to authorize improvements in public transit, whereas a port may not have the same authority. Moreover, unlike GHG emissions, there are no specific state or federal guidelines for adaptation planning. In general, 
both the US Federal-level National Environmental Policy Act (NEPA) and Statelevel CEQA require a project proponent to evaluate potential impacts of locating individual development projects in areas potentially vulnerable to climate change effects but do not require an overall master plan for adaptation. The adaptation portion of the Climate Plan addresses the need for an overall plan for climate change impacts and evaluates and prioritizes key vulnerabilities within Port tidelands that require further analysis and adaptation strategies in order to retain operational, recreational and natural resources functions.

The steps followed in the development of the Climate Plan to address climate change adaptation were informed by guidance provided in NEPA, CEQA, the California Adaptation Strategy [14], and on-going collaboration with the ICLEILocal Governments for Sustainability Sea Level Rise Adaptation Strategy [8], the California SLR Interim Guidance [15] as well as other available documentation. Based on the Port's location and operational activity and on planning work conducted to date, SLR is the primary climate change impact which will affect the Port. The California SLR Interim Guidance recommends consideration of timeframes, adaptive capacity, and risk tolerance when selecting estimates of sea level rise. The Climate Plan incorporates the risk assessment approach outlined in the SLR Interim Guidance, and then provides a quantitative assessment of vulnerabilities and risks due to SLR. The two main objectives of the quantitative vulnerability and risk analysis for SLR help the Port to better understand relative operational risks are: 1) to help the Port to better understand relative operational risks from SLR in 2050 and 2100 and 2) to inform policymaking and develop a framework to apply adaptation strategies during implementation of the Climate Plan. To meet these objectives, the following four step methodology was used.

\subsection{Step 1: develop GIS model to map SLR}

Geographic Information System (GIS) data were collected to address the impact of SLR for areas within the Port's jurisdiction and in San Diego Bay. These datasets include location-specific information on the Port's jurisdictional boundary, Port-specific land use types, coastal and marine habitats and protected areas, Precise Planning Districts ("Planning Districts") used in the Port's Master Plan, the stormwater conveyance system, elevation monuments (control points), LIDAR-derived elevation contours, San Diego Bay bathymetry, and aerial photography. Using the elevation contours, control points, and bathymetric data, a TIN (Triangulated Irregular Network) elevation dataset was created to visualize the San Diego Bay, tidelands, and surrounding upland area. The TIN was converted to a raster DEM (Digital Elevation Model) with 30-foot spatial resolution using the ArcGIS Spatial Analyst extension. Using the DEM elevation model, areas potentially subjected to inundation under each SLR scenario were then calculated for all Port lands in the GIS using the predicted SLR elevation.

The methods used in the Climate Plan to map predicted SLR inundation in 2050 (2.85 $\mathrm{m}$ above global mean sea level) and 2100 (3.85 $\mathrm{m}$ above global mean sea level) were developed to be consistent with best available science and 
projections, including the local sea level height model created by Dr R Gersberg (San Diego State University) [16], the California SLR Interim Guidance [15], and the information presented in the Sea Level Rise Adaptation Strategy for San Diego Bay [8]. Consistent with the SLR Interim Guidance recommendation to ensure a risk averse approach for planning, the predicted sea level height model for the 2050 and 2100 scenarios presented includes sea level rise along with a 100-year exceedance of the highest high tide event. This model includes recorded local events such as storm surges, wave run-up, El Niño events and circulation patterns.

Not all areas below the elevation of the SLR predictions are expected to be inundated. The presence of protective seawalls, levees, or other naturally occurring topographic barriers may act to protect localized areas from SLR, despite the fact that these areas have a base elevation currently below the calculated inundation levels. Since these barriers were not accounted for during the creation of the elevation dataset described above, both the 2050 and 2100 SLR inundation layers were overlain with elevation contours and aerial photographs. All potential inundation areas were reviewed manually to determine if they could be influenced by the presence of a barrier. If barriers were observed in the contours and/or aerial photographs, the area of the inundation layer was modified to limit the extent of the inundation. The result of this analysis was a modified, inundation layer for both the 2050 and 2100 scenarios that account for physical barriers to SLR.

For consistency with the Port's planning processes, the analysis was primarily designed to spatially coincide with the ten Planning Districts identified in the Port Master Plan [17]. Furthermore, Port lands were categorized into four key Port functions: Working Port (e.g., businesses including maritime operations, restaurants, and hotels), Safe Port (e.g., transportation corridors), Green Port (e.g., natural areas), and Public Port (e.g., golf course and parks). To quantitatively determine areas vulnerable to SLR and to prioritize risk, Port functions were associated with spatially explicit land use designations and habitat characteristics as part of the GIS assessment. For example, those uses identified in the Port Master Plan as "estuary", "wetland", "habitat replacement", and "salt pond" were categorized in the Green Port function. The total area (in acres) representing each Port function was summarized on a Planning District and Port-wide basis.

The inundation layers for 2050 and 2100 were then overlain on the Port functions to determine those functions that would be affected by SLR. The acreage of inundation for each Port function was then calculated and compared to the total acreage of each Planning District and Port-wide. The percentages of inundation of each Port function for each SLR scenario were then used in the subsequent analysis to determine likelihood and consequence values.

\subsection{Step 2: assess likelihood of SLR}

The 'likelihood' of inundation is a representation of the relative susceptibility of Port functions to inundation as predicted in the 2050 and 2100 SLR scenarios. In the context of this analysis, likelihood is not a measure of probability that an area 
will be inundated in 2050 or 2100 . Rather, likelihood is a relative measurement of the extent of each Port function inundated by SLR within a specific Planning District. This definition of likelihood is based on an assumption that the greater the inundation extent for each Port function determined in the GIS analysis, the more likely that Port function will be impacted on a regular basis. A calculation of probability in all areas of the San Diego Bay by property would have been too complex to perform for the scope of this work as well as being relatively uncertain given the current state of SLR science. Inundation likelihoods were categorized as Almost Certain ( $>90 \%$ susceptibility), Probable (50-90\% susceptibility), Possible (10-50\% susceptibility), Unlikely (1-10\% susceptibility) and Rare ( $<1 \%$ susceptibility).

\subsection{Step 3: assess consequence of SLR}

The 'consequence' of inundation represents the severity of impacts resulting from SLR in the 2050 and 2100 scenarios. The California SLR Interim Guidance, suggests that in order to adequately assess the potential consequence of SLR, especially in timeframes beyond 2050 (due to more uncertainty regarding future climate change impacts and predicted SLR), both adaptive capacity and the potential impacts of SLR to public health and safety, public investments, and the environment need to be considered. Adaptive capacity is the ability of a system to respond to climate change and moderate potential damages, take advantage of opportunities, and cope with the consequences. For the purposes of assessing risks associated with SLR for the Port Climate Plan, it was assumed that there is currently a relatively low adaptive capacity throughout the Port's jurisdiction and other waterfront properties due to the lack of undeveloped land area immediately adjacent to the bay available for relocation of existing Port functions. .

Consequence ratings (ranging from 1-5) were assigned by comparing a Port function's percentage of inundation within each Planning District to the percentage of a Port function's inundation Port-wide. This comparison is used to normalize the area of each Planning District. Therefore, a higher consequence rating is assigned to those Port functions which are impacted by SLR to a greater extent both within the Planning District and Port-wide. Conversely, those Port functions which may be impacted to a great extent in a single Planning District but less so Port-wide are assigned a lower consequence rating. Although Portwide impacts are the primary determinant of the consequence rating, Planning District-specific impacts are used as a secondary determinant on the assumption that a heavy impact to a Planning District's Port function should be considered even if the Port-wide impact for that function is relatively small.

\subsection{Step 4: determine risk to port functions}

A risk matrix combining the likelihood and consequence ratings was used to determine a final risk value for each Port function per Planning District. Figure 1 shows this matrix. The rating provides a means to prioritize potential risks of SLR inundation to Port functions within the Port's jurisdiction. Risks are 
categorized from "Low" to "Very High" and serve as a planning tool for prioritization of action. The risks identified through this process can be analysed in order of priority to determine appropriate and feasible adaptation strategies to increase adaptive capacity. The 'High' and 'Very High' risks determined in the 2050 SLR scenario were recommended to be prioritized over the 2100 SLR scenarios given the more immediate timeframe.

\begin{tabular}{|c|c|c|c|c|c|c|}
\hline & & \multicolumn{5}{|c|}{ CONSEQUENCE } \\
\cline { 3 - 7 } & & $\mathbf{1}$ & $\mathbf{2}$ & $\mathbf{3}$ & $\mathbf{4}$ & $\mathbf{5}$ \\
\hline \multirow{3}{*}{$\mathbf{8}$} & $\mathbf{5}$ & Medium & High & Very high & Very high & Very high \\
\cline { 2 - 7 } & $\mathbf{4}$ & Medium & Medium & High & Very high & Very high \\
\cline { 2 - 7 } & $\mathbf{3}$ & Low & Medium & Medium & High & Very high \\
\cline { 2 - 7 } \\
\cline { 2 - 7 } & $\mathbf{2}$ & Low & Low & Medium & Medium & High \\
\cline { 2 - 7 } & $\mathbf{1}$ & N/A & Low & Low & Medium & Medium \\
\hline
\end{tabular}

Figure 1: $\quad$ Inundation risk rating (Risk $=$ Likelihood $\mathrm{x}$ Consequence).

Risk assessment summary tables were then generated for each Planning District to incorporate the results of the GIS analysis identifying the percentage of each Port function potentially inundated per Planning District and Port-wide. In addition, the tables provide details of the land uses, habitats, roads, and infrastructure which may be affected by SLR. Lastly, an initial list of adaptation strategies was developed for each Port function to respond to inundation.

Multiple habitats and protection areas within the Bay, but outside of the Port's jurisdiction, are also predicted to experience inundation in 2050/2100. These natural resources are co-managed by multiple agencies with the understanding that the entire ecosystem is composed of individual habitats which cross jurisdictional boundaries. Beach dune and salt marsh habitats are projected to be impacted by flooding with limited space for landward migration. Eelgrass, which is a sub-tidal habitat, will also likely experience further inundation with unforeseen consequences. Given this, the Port is planning to work with the responsibility agencies to further evaluate potential adaptation strategies to address these areas outside of the Port's jurisdiction.

There are some significant changes in risk within individual Planning Districts between 2050 and 2100 as the extent of SLR is predicted to increase. Planning Districts with high and very high risk in 2050 are mainly in the functions of Working Port and Green Port. Risk to the Working Port function is predominately associated with water-based uses affecting marinas, anchorages, berthing areas along marine terminals, or to waterfront businesses and/or operations with infrastructure immediately adjacent to the shore. Habitats associated with the Green Port function most at risk during 2050 include eelgrass and beach dune. The effect of SLR and climate change on habitats is complex and is dependent upon a number of factors associated with the specific needs of the habitat. For example, eelgrass is a submerged seagrass predominately present in subtidal areas of San Diego Bay. Increased sea level affecting depth, 
light, temperature, etc. during 2050 may have variable effects on the survival of eelgrass throughout the Bay. Likewise, beach dune habitats may become inundated resulting in a loss of area for nesting, roosting, and foraging for birds as well as a loss of dune-dwelling plants.

The Safe Port function is dependent on transportation networks providing access for security and safety operations. Most Planning Districts are predicted to have no impact or low impact in 2050 to the Safe Port function as a result of limited inundation or flooding to transportation networks. Risk to the Public Port function is variable among Planning Districts and ranges from no impacts in the South Bay Saltlands to very high risk located at the Centre City Embarcadero, where considerable tourism from downtown San Diego conventions and outdoor events is concentrated. Risk to the Public Port function is determined by the amount of park/plaza and open space uses within an area that is subject to inundation.

In 2100, increased inundation associated with SLR is predicted to be widespread throughout the Port's jurisdiction and in and around San Diego Bay. In many areas, inundation is predicted to extend beyond the Port's jurisdiction. All of the Port functions within most Planning Districts were determined to be at high or very high risk by 2100 .

\section{The NESA framework}

The above example from the Port of San Diego work provides an approach to establish physical vulnerabilities and risks from SLR to key coastal activities at a county or regional scale. A logical next step is then to correlate and compare these risks from a financial perspective. The NESA approach unites the full suite of issues with a financial component (social, economic and environmental) for decision making when quantifying costs and benefits across a variety of land use types.

NESA is a well-established analytical framework that can incorporate a wide range of ecosystem service and financial/land management information. Figure 2 provides a conceptual illustration of the NESA framework, comprising three data bases that are combined to produce a baseline ecosystem service assessment. This is the information base used to evaluate alternative investment and management strategies by comparing them to existing or predicted baseline conditions. For this approach to be successful, it is critical that information is developed within a framework where information is relational so that results are comparable across the ecosystem services, landscape and facility or management activities. Comparisons can then be made at the same scale and with the same levels of precision. The NESA framework can accommodate a wide range of resolution for data, including GIS data.

NESA allows for the formal quantification or semi-quantification of socioeconomic and ecosystem service values associated with different land (water) cover types, land (water) uses and activities or facilities. The current and future influences such as climate change and management actions, within each cover and activity type are then compared to a baseline. The approach governs 
the collection and analysis of data on a detailed (e.g. facility or activity) scale, establishing existing (baseline), and potential future (mitigation and conservation) capacities. The results are expressed in standard metrics or "currencies" (e.g. services provided by an acre of land or a particular facility in a year) so that socioeconomic and ecosystem levels can be estimated and compared.

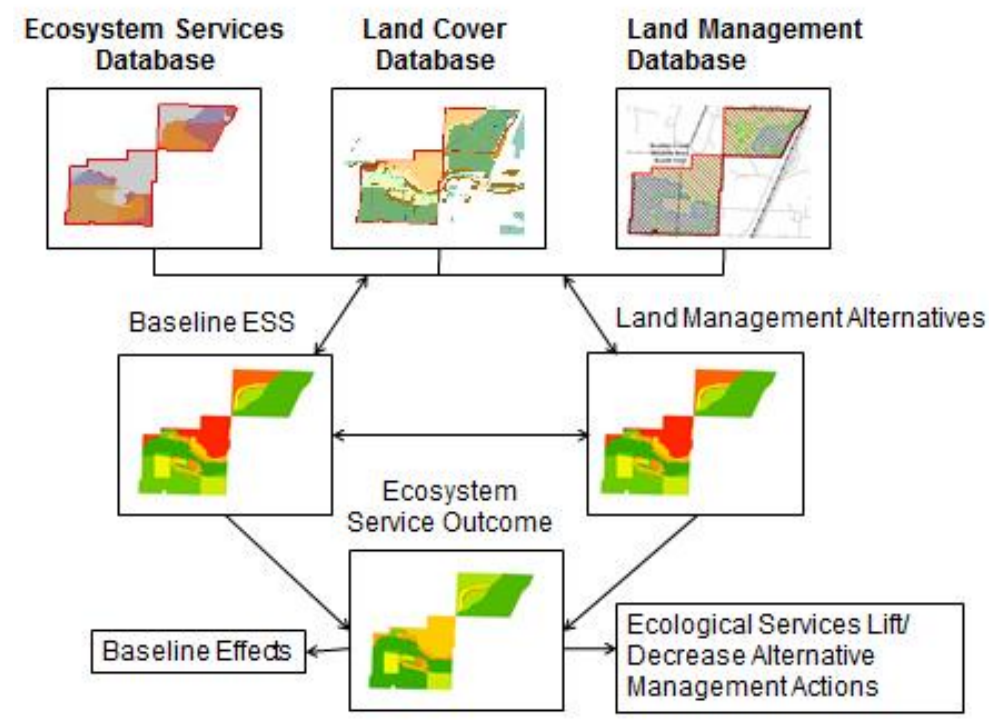

Figure 2: Schematic of data base construction and analysis.

Efficient development of the framework normally involves two initial steps including 1) a screening to identify data gaps and focus data collection and 2) development of the initial database that will serve as the foundation for the alternative analysis. The framework and database then provides for analysis of alternatives for near-term and long-term investment. Table 1 provides an overview of the different services that could be evaluated for different aspects of port functions for the Port of San Diego example.

The Port of San Diego case study used an initial screening of lands subject to induration to determine risk levels. As was discussed in the GIS methodology, a yes/no decision was made on each property and whether it was subject to potentially extended inundation during a future storm event with SLR considered. A five point scale for the consequences of inundation was then used to provide an initial assessment of the severity of the impact. However, there is no attempt to normalize the impacts across land use types and port functions in the case study. For example, it is not known if a ranking of "five" in the Public Use category is the financial equivalent of a similar ranking for Port Operations, etc. The next step to more fully evaluate adaptation strategy alternatives would be more precise quantification of the consequences of impacts in a common currency that the NESA approach provides. 
Table 1: Overview of different services that could be evaluated for different aspects of port functions.

\begin{tabular}{|c|c|}
\hline Port Function & Potential Metric \\
\hline $\begin{array}{c}\text { Port Operations } \\
\text { (Working Port) }\end{array}$ & $\begin{array}{c}\text { Annual Revenue; Jobs Supported; Occupancy; } \\
\text { metric tons or TEUs imported/exported }\end{array}$ \\
\hline Port Safety (Safe Port) & Annual Injuries; Illnesses; Fatalities \\
\hline $\begin{array}{c}\text { Port Sustainability } \\
\text { (Green Port) }\end{array}$ & Habitat; Fish Populations; Air Quality \\
\hline Public Uses (Public Port) & Annual Visitors; Recreational Trips \\
\hline
\end{tabular}

An essential component of the NESA approach is the recognition that the value of natural resource assets is defined by the quality and quantity of the 'service flows' generated by an ecosystem. As environmental markets emerge to capture the inherent value of these ecosystem assets as they pertain to private land stewardship, it is more important than ever for decision makers to understand how their choices can affect the social, environmental and economic benefits associated with an ecological asset as well as their business assets. NESA builds on approaches developed over many years such as Natural Resource Damage Assessment (NRDA) quantification of environmental gains and losses used by the US federal government for environmental damage assessments, benefit-cost analysis for public infrastructure used by the US Army Corps of Engineers [18] for project evaluation, new International Finance Corporation (IFC) performance standards that screen for ecosystem service risks and impacts, and the Millennium Ecosystem Assessment framework [19].

\section{Conclusions}

This paper highlights the risks posed by climate change to ports, specifically from sea level rise, and provides a method to evaluate and quantify these risks in an understandable and consistent manner. Port authorities have many issues to consider as sea level rise trends continue in the decades ahead. An essential first step is to assess future sea level ranges combined with storm surges and portray this information visually and spatially so that all affected parties - port tenants, municipal authorities, port operators, and the general public - can work off a common understanding to begin the long term planning necessary to keep ahead of the mounting problems associated with climate change. The GIS-based methodology provided in the case study here was specific to the Port of San Diego and the activities and land use types around San Diego Bay but can be readily tailored for use in many other coastal jurisdictions to establish vulnerabilities and general risks at the port-wide or regional level. The methodology also allows for evaluation of risk at a regional level without having to perform time-consuming and costly risk assessments of each property potentially affected by sea level rise and flooding. 
Once these vulnerabilities and risks are established, an essential part of developing prioritized adaptation strategies is a good understanding of the complete range of the financial impacts from climate change across different activities and land uses - port business, public uses, and ecosystem services. The NESA framework presented here allows coastal jurisdictions such as port authorities to more thoroughly evaluate the costs and benefits of a fuller range of adaptation strategies on a common platform. se of the NESA approach can also address public concerns that their recreational uses and the ecological health of the region are being prioritized in a consistent manner as port business is evaluated.

\section{References}

[1] McLaughlin, B., S. Murrell, and S. DesRoches. Anticipating Climate Change. Civil Engineering. April 2011.

[2] Port of New York and New Jersey accessed at http://www.panynj.gov/port/newsletter.html?tabnum=4\#content

[3] Mandryk, W. 2009. Measuring Global Seaborne Trade, Presented at the World Maritime Statistics Forum, New Orleans, 2009.

[4] US Maritime Administration. U.S. Waterborne Foreign Trade by Trading Partners (Updated 06/13/11) www.marad.dot.gov/library_landing_page/ data_and_statistics/Data_and_Statistics.htm

[5] Martin Associates. The Local and Regional Economic Impacts of the US Deepwater Port System, 2007. American Association of Port Authorities. Last modified June 6, 2008. aapa.files.cms-plus.com/PDFs/Martin Associates.pdf Accessed August 1, 2012.

[6] Rahmstorf, S. A new view on sea level rise, Nature Reports Climate Change, 4, 44-45, 2010.

[7] Bromirski, P. D., A. J. Miller, and R. E. Flick, 2012. Understanding North Pacific sea level trends, Eos Trans. AGU, 93(27), 249, doi:10.1029/2012EO270001. www.agu.org/pubs/crossref/2012/2012EO27 0001.shtml Accessed August 1, 2012.

[8] Kirshen, P., C. Watson, E. Douglas, A. Gontz, J. Lee, and Y. Tian. Mitigation and Adaptation Strategies for Global Change, "Coastal Flooding in the Northeastern United States due to Climate Change." Last modified July 2007. www.northeastclimateimpacts.org/pdf/miti/ kirshen_et_al.pdf Accessed August 1, 2012.

[9] ICLEI Local Governments for Sustainability - USA. Sea Level Rise Adaptation Strategy for San Diego Bay. San Diego: The San Diego Foundation 2012. www.icleiusa.org/climate_and_energy/Climate_ Adaptation_Guidance/san-diego-bay-sea-level-rise-adaptation-strategy1/san-diego-bay-sea-level-rise-adaptation-strategy Accessed August 1, 2012.

[10] Hanson, S., R. Nicholls, N. Ranger, S. Hallegate, J. Corfee-Morlot, C. Herweijer, and J. Chateau. A global ranking of port cities with high exposure to climate extremes, Climate Change, 104, 89-111, 2011. 
[11] Lempert, R., and K. Keller. California Energy Commission, "Characterizing Uncertain Sea Level Rise Projections to Support Investment Decisions." Last modified July 2012. www.energy.ca.gov/2012publications/CEC-500-2012-056/CEC-500-2012056.pdf. Accessed August 1, 2012.

[12] Hooven, C., J. Hirsch, M. White, et. al. Port of San Diego. "Port of San Diego Climate Mitigation and Adaption Plan." events.awma.org /GHG2011/Abstracts/Session 9/Abstract \#9/Extended Abstract_9.pdf Accessed August 1, 2012.

[13] Crossett, K., T. J. Culliton, P. C. Wiley, T. R. Goodspeed. Population Trends Along the Coastal United States: 1980-2008. NOAA National Ocean Service. Accessed August 1, 2012. oceanservice.noaa.gov $/$ programs $/ \mathrm{mb} / \mathrm{pdfs} /$ coastal_pop_trends_complete.pdf

[14] NOAA's Office of Ocean and Coastal Resource Management and the Coastal States Organization. Envisioning our Coastal Future: Principals for Advancing the Coastal Zone Management Act, coastalmanagement.noaa.gov/czm/media/PhaseIII.pdf Accessed August 1, 2012.

[15] State of California. 2009 California Climate Adaptation Strategy; a Report to the Governor of the State of California in Response to Executive Order S-13-2008. Sacramento: CA Natural Resources Agency, 2009.

[16] California Climate Action Team (CO-CAT), 2010. Sea Level Rise Interim Guidance Document. Sea Level Rise Task Force of the Coastal and Ocean Working Group. October. www.slc.ca.gov/Sea_Level_Rise/SLR Guidance_Document_SAT_Responses.pdf Accessed July 24, 2012.

[17] Gersberg, R. Personal communication. 24 November 2010. Description of methods for creating the inundation maps for sea level rise scenarios in San Diego Bay. Email message to Dr. Emily Young, San Diego Foundation. Wednesday, 2010.

[18] San Diego Unified Port District. Port Master Plan, San Diego Unified Port District. San Diego: Port of San Diego Land Use Planning Department, 2010.

[19] Davis, T.B., et al. 2009. Principles and Guidelines for Evaluating Federal Water Projects: U.S. Army Corps of Engineers Planning and the Use of Benefit Cost Analysis: A Report for the Congressional Research Service. University of Washington, Seattle, WA.

[20] Millennium Ecosystem Assessment. Ecosystems and Human Well Being: Synthesis. Island Press, Washington, D.C., 2005. 